This is the peer reviewed version of the following article:

Del Rey, E. and Estevan, F.Assessing higher education policy in Brazil: a mixed oligopoly approach, The B.E. Journal of Economic Analysis and Policy, Vol. 20(1), January 2020, pages XXX-XXX.

This article has been published in final form at https://doi.org/10.1515/bejeap-2019-0240. This article may be used for non-commercial purposes in accordance with De Gruyter Repository Policy. 


\title{
Assessing higher education policy in Brazil: a mixed oligopoly approach*
}

\author{
Elena Del Rey ${ }^{\dagger}$ and Fernanda Estevan ${ }^{\ddagger}$
}

${ }^{*}$ We thank Tiago Cavalcanti, Raquel Fernández, Fabio Kon, Caio Lente, Gabriel Madeira, Dilip Mookherjee, João Ramos, Marc Rysman, and José Ignacio Silva for helpful comments and support. Financial support from the Spanish Ministry of Science (project ECO2016-76255-P), Sao Paulo Research Foundation (FAPESP, proc. 2015/21640-3), British Academy and the Newton Fund (Newton Advanced Fellowship, AF140079), and $\mathrm{CNPq}$ are gratefully acknowledged. Estevan was a visiting scholar at the Institute for Economic Development at Boston University while working on this project. The authors are pleased to acknowledge that the computational work reported on in this paper was performed on the Shared Computing Cluster, which is administered by Boston University's Research Computing Services (www.bu.edu/tech/support/research/).

${ }^{\dagger}$ Facultat de Ciències Econòmiques i Empresarials. Carrer de la Universitat de Girona, 10. 17003 Girona, Spain. E-mail: elena.delrey@udg.edu.

${ }^{\ddagger}$ Sao Paulo School of Economics - FGV, Rua Itapeva, 474, Sao Paulo, SP, Brazil; email: fernanda.estevan@fgv.br. 


\begin{abstract}
Higher education is increasingly provided by both public and private universities, in particular in the developing world. Considering a mixed oligopoly setting and inspired by the Brazilian context, we explore the relative merits of some frequently used higher education policies in a context where a high-quality public university interacts with a lower-quality private university. We calibrate the model to match relevant values of Brazilian earnings and educational distribution. Subsidising private university tuition fees increases participation, but many high ability students remain excluded, especially if the subsidy is substantial. Affirmative action improves the surplus associated with the public university system, as more high ability individuals attend the public university, but virtually does not increase higher education participation. Although an expansion of public university places induces a reduction in private university fees, total university enrolment grows slowly, and many high-ability individuals cannot obtain a university education.
\end{abstract}

Keywords: higher education, exams, fees, borrowing constraints.

JEL Classification: H44, I22. 


\section{Introduction}

Higher education has traditionally been seen as an inherently public sector activity in many countries. In the last decades, a flourishing private university sector has made of higher education a dual-sector phenomenon globally (Levy, 2018). In developing countries, the private university sector expansion has been particularly rapid, as progress achieved in secondary schooling generated a massive demand for higher education that the public sector was not ready to accommodate. Thus, understanding the interactions between the public and the private university sectors have become increasingly relevant to assess the effects of higher education policies, especially in developing countries.

In this paper, we consider the existence of a public and a private university sector that compete for a continuum of students characterised by ability and income levels. We extend the model in Fernandez and Gali (1999) and ? to allow for the interaction between the public and the private university sectors considering the main features of the Brazilian higher education sector. We then simulate different policies and assess their impact on the universities' decision variables and payoffs, and on student allocation.

Brazil has an emblematic higher education system in regional terms. As in many Latin American countries, public universities typically have a better reputation than private universities. ${ }^{1}$ Among the 24 Brazilian universities in the group of 50 top-ranked Latin American universities, only three are private. ${ }^{2}$ The differences in funding between public and private universities are substantial. While the per-student cost of public universities was around US\$ 10,000 per year in 2010 (INEP/MEC, 2010), the estimated average tuition fee paid by an individual enrolled in a private university was $35 \%$ of that amount. ${ }^{3}$

\footnotetext{
${ }^{1}$ To be sure, there are notable exceptions to this rule. Still, of the 50 best ranked Latin American universities, 35 are public (Times Higher Education, 2019).

${ }^{2}$ For comparison, only eight out of the 50 best ranked US universities are public (Times Higher Education, 2019).

${ }^{3}$ According to INEP/MEC (2010), the cost per public university student was $\mathrm{R} \$ 16,541$ in 2010 . We converted that amount using the exchange rate on 31 December 2010 of US $\$ 1=\mathrm{R} \$ 1.6618$. We calculate
} 
The Brazilian private higher education system is sizeable, as public universities enrol only $25 \%$ of university students. Public universities apply entrance exams, which can be very competitive, or use the ENEM (end-of-high-school national test) as a selection mechanism. They do not charge tuition fees. Private universities are, in contrast, mostly characterised by lower education quality, in part because they tend to attract weaker students. While they may use ENEM or other entrance exams, the requirements needed for access are typically quite low. Private universities charge tuition fees.

Since public universities require higher scores for admission, they tend to attract students coming from more privileged backgrounds, who have completed high school in a private institution. Until recently, students from poor backgrounds were practically excluded from university attendance since they could neither afford to attend a private high school or pay tuition fees at private universities. Such a situation goes against the broad consensus that ability to pay should not determine access to higher education. An allocation of students to universities based on ability only is essential to level opportunities and maximise the surplus of the higher education sector.

Like many developing countries, Brazil has recently implemented several policies as an attempt to level the playing field for underprivileged individuals in the higher education system and increase the number of university graduates (Bertrand et al., 2010; Estevan et al., 2019). We focus on means-tested scholarships for attending the private university, affirmative action for disadvantaged students and an increase in public university capacity. ${ }^{4}$ While the most natural way to address credit constraints appears to be a loan system, and some developed countries have implemented income-contingent loans, the experiences with students loans have proved challenging in developing countries. In particular, a robust legal

the estimates for private university tuition fees by using the total amount spent on private higher education according to Menezes-Filho and Nunez (2012) and total private university enrolment in 2010.

${ }^{4}$ Ramos and Herskovic (2017) investigate the impact of affirmative action policies introduced in Brazil on longer-term educational outcomes and welfare. 
framework and functional judicial system are essential requirements for a workable loan scheme, and these are often lacking in the developing world (Chapman, 2016). ${ }^{5}$

Together with the increased number of students completing secondary schooling, these public policies have enabled the number of students enrolled in higher education to go from 3.8 million in 2003 to 7.3 million in 2013 in Brazil. It is not sure, however, that this surge has benefited the ablest or increased the surplus associated with higher education. In particular, universities' reactions to the policies can sometimes reverse the effects of public policies. For example, we will show that private universities may alter tuition fees in the presence of subsidies for private university fees, public university capacity expansions or affirmative action policies.

Our model incorporates several features of the Brazilian higher education system and studies the effects of these different policies in a mixed oligopoly environment. We aim to track changes in the allocation of students to each university sector and, as a consequence, in the surplus generated, i.e., the difference between human capital produced and the cost incurred. To do so, we assume that universities' quality levels are exogenously given. ${ }^{6}$ These qualities may be thought of as reputation, which is relatively stable in the short/medium run.

We consider the existence of a high-quality public university sector and a low-quality private university sector that compete for a continuum of students characterised by ability and income levels. ${ }^{7}$

\footnotetext{
${ }^{5}$ For instance, Brazil has a public loan system for private university students, Fies. Currently, two-thirds of loan recipients are unable to repay their loans. Due to the lack of repayment enforcement, the program became a scholarship program virtually.

${ }^{6}$ Unlike Cremer and Maldonado (2013) and Romero and Del Rey (2004), we do not consider peer group effects, which is consistent with our assumption of exogenous university quality. While they focus on the characterisation of the market equilibrium, our strategy is to take the basic structure of the market as given and explore the effects of alternative policies in the short term. We conjecture that peer group effects would not change the behaviour of the public firm as we model it. In contrast, the existence of peer effects could provide incentives for the private university to reduce fees or use selective exams to attract higher ability students.

${ }^{7}$ While this setting is a plausible (simplified) depiction of the Brazilian higher education system, it does not represent the reality in many countries where private universities are generally of higher quality than
} 
The public university, financed by governmental funds, has fixed capacity and charges no fees. To fill capacity, it runs an admission exam to select all students that obtain at least a given score. In contrast, the private university does not have capacity constraints, receives no public funding, and charges tuition fees to maximise profits. Profit maximisation is a standard (simplifying) assumption in the mixed oligopoly literature to oppose the goals of the public firm. The critical point is that, unlike the public university, the private university cares for revenues. In the Brazilian setting, this assumption is not far from reality (Knobel and Verhine, 2017), also because the non-profit sector tends to behave similarly to the forprofit institutions in many dimensions (Salto, 2018). ${ }^{8}$

Individuals get utility from attending university, which depends on the human capital obtained, and tuition fees paid, or expenditures made to pass the admission exam. Indeed, individuals pay a cost to prepare for the admission exam. Like Fernandez and Gali (1999), we assume an admission exam technology that transforms ability and expenditures into a score. The spending required to pass the exam is decreasing in ability and increasing in the minimum threshold score.

We characterise the benchmark allocation as the situation in which students sort into the public and the private university based on ability only. In the absence of perfect capital markets, the individual is subject to an income constraint, and can only afford a university education provided that her initial income can pay for tuition fees or expenditures related to the admission exam preparation. Thus, individuals have in principle three choices: enrol at the public university, enrol at the private university, or do not attain higher education.

As a full characterisation of equilibrium properties is intractable, we perform numerical simulations to explore the relative merits of some of the most frequently used policies to public universities. However, the simulation tools we develop to analyse our context can be easily adapted to investigate alternative settings.

${ }^{8}$ An article in the New York Times (Horch, 2014) gives full credit to our description of the higher education market in Brazil. 
address access to higher education accounting for the reactions of the universities in a mixed oligopoly environment.

Our results show that subsidising private university fees can be very effective in raising enrolments in higher education. However, if the subsidy is too generous, the private university will increase its fees, and some poor students (but not so poor to receive the allowance) will not be able to afford a university education. Students from higher-income backgrounds remain, however, over-represented mainly at the public university. Affirmative action policies can equilibrate the profile of students enrolled in the public system, provided that the reduction in the admission requirements is sufficiently large. This policy thus emerges as the most adequate to increase the surplus associated with the public university system and is revenue neutral. However, the private university will raise fees as a response, harming some lower-income students. Finally, increasing public university places benefits students from higher-income backgrounds most, but is also the most costly alternative.

We organise the rest of the paper as follows. In Section 2 we comment on the related literature. We present the model in Section 3, the calibration and the simulations of the benchmark and baselines cases of the Brazilian higher education sector in Section 4 . We analyse the different policies in Section 5 and show that our results are robust to alternative assumptions regarding the income-ability correlation in Section 6. Finally, Section 7 concludes.

\section{Related literature}

In addition to the works already mentioned, our contribution is related to two strands of literature. The first is on mixed oligopolies with differentiated firms, that, to the best of our knowledge, goes back to Cremer et al. (1991), for horizontally differentiated products, and Grilo (1994), for vertically differentiated products. In both cases, competition between 
a private and a public firm can generate a higher surplus than competition between two private firms. Cremer et al. (1991) also show that this result still holds when one public firm competes with a large number of private firms.

Delbono et al. (1996) model a duopoly with a public and a private firm competing in quality and price. When firms move simultaneously in each stage, there are two subgames perfect Nash equilibria entailing opposite quality rankings. If the public firm has a move advantage, there is a unique Stackelberg equilibrium where the public firm provides the higher quality. More recently, Laine and Ma (2017) consider a similar model where consumers display different preferences for quality and also find multiple subgame perfect equilibria. In these circumstances, it is impossible to predict or provide conditions under which public quality will be larger or lower than the private quality. ${ }^{9}$ Benassi et al. (2016) consider a short-run approach, by taking quality levels as given and focus on the characterisation of the price equilibrium. ${ }^{10}$

Mixed oligopoly models have been notably applied to the analysis of privatisation (Ishibashi and Kaneko, 2008), the health care market (Jofre-Bonet, 2000; Sanjo, 2009), and the market for higher education. The higher education market bears some particularities. Unlike compulsory education and health provision, universal coverage is generally not desirable in the higher education market. Indeed, output depends on individual ability and, for some ability levels, getting no higher education is an efficient outcome. Also, credit constraints prevent some individuals from accessing their first best, and second-best choices potentially determine effective demand. Moreover, in addition to choosing quality and price, each higher education institution can also ration demand by setting admission standards. Finally, like in other education levels, peer group effects can be crucial in the determination of quality.

\footnotetext{
${ }^{9}$ Barigozzi and Ma (2018) propose a method to characterise equilibria in differentiated markets that solves the tractability-generality dilemma generally encountered in this literature.

${ }^{10}$ In the context of higher education, Del Rey (2009) analyses, separately, two equilibria: one with higher (exogenous) public quality and one with lower (exogenous) public quality, and shows that public university fees can be welfare-enhancing when they induce the private university to increase enrolments.
} 
Oliveira (2006), Romero and Del Rey (2004), Cremer and Maldonado (2013), and Tomori (2018) have attempted to account for these features of higher education markets. In Brunello and Rocco (2008), a public and a private school compete in price and educational standard, and the latter is chosen by majority voting. In this context, there are also two equilibria, one where the public school is the high-quality school and another one where it is the lower quality school. ${ }^{11}$ As we do not intend to characterise all possible outcomes but to analyse the effect of a policy when the public university provides higher quality than the private university, it makes sense to take the quality ranking as given.

The second strand of the literature uses theoretical and computational equilibrium models to simulate education policies. In particular, our contribution is closest in spirit to Epple et al. (2017) that develop a general equilibrium model of the market for undergraduate studies in the US. In their model, public universities maximise the aggregate achievement of in-state students, receive public subsidies, and face regulated tuition caps. Private colleges are in monopolistic competition and maximise quality, which is a function of the ability of their student body and resources. ${ }^{12}$ After calibrating the model, Epple et al. (2017) evaluate the effects of two policy changes: an increase in federal aid available to students from both types of universities, and a reduction in the per-student state subsidy accompanied by an increase in tuition to in-state and out-of-state students. They find that reducing federal or state aid reduces attendance substantially, mainly by poor students. Also, a reduction in the support to state colleges induces private colleges to increase enrolment moderately and improve quality.

Our approach is less ambitious than Epple et al. (2017). Similar to Benassi et al. (2016), we focus on a short run partial equilibrium approach, which reproduces the main features of the Brazilian higher education system. Also, like Brunello and Rocco (2008), we consider a

\footnotetext{
${ }^{11}$ De Fraja (2004) explores the reasons why public and private schools coexist at all.

${ }^{12}$ Epple and Romano (1998) use a competitive model for the interaction between public and private schools to analyse the effects of vouchers.
} 
simplified market for higher education with only one public and one private university. Thus, a significant difference with respect to Epple et al. (2017) is that we rule out differentiation in private university price levels.

\section{The model}

In this section, we modify the framework by ? to a context where there is a high-quality public university $\theta_{H}$ and a low-quality private university $\theta_{L}$.

\subsection{Students and Universities}

There is a continuum of students characterised by an ability level $a \in[\underline{a}, \bar{a}]$ and an income level $w \in[\underline{w}, \bar{w}]$. The joint marginal distribution function of ability and income is given by $f(a, w)$ and the cumulative distribution by $F\left(a^{\prime}, w^{\prime}\right)=\int_{0}^{a^{\prime}} \int_{0}^{w^{\prime}} f(a, w) d w d a$. Our framework allows for ability and income to be correlated or not. In both cases, education outcomes depend on income, as education investments are costly.

The private university has an unconstrained capacity, is non-selective, and maximises profits by charging tuition fees, $p_{L}$. The public university faces a capacity constraint $\kappa$ and receives only governmental funds, i.e., does not charge tuition fees. To select students, it organises an admission exam and admits all applicants that obtain at least score $v$. The per-student cost is $c\left(\theta_{j}\right)$ with $j \in[H, L]$, increasing and convex in $\theta_{j}$. The assumption that $\theta_{H}>\theta_{L}$ implies that the per-student cost is higher at the public university as compared to the private university. ${ }^{13}$

The public university admission exam function $V(a, e)=v\left(\right.$ with $\left.V_{a} \geq 0, V_{e} \geq 0, V_{a e} \geq 0\right)$ transforms ability and expenditures $e$ into a score $v$. Thus, the expenditure level required by an individual of ability a to obtain score $V(a, e)$ is implicitly defined by $V(a, e(v, a))=v$.

\footnotetext{
${ }^{13}$ As mentioned in Section 1, this is the case in the Brazilian higher education setting.
} 
As ? and Fernandez and Gali (1999), we work with the dual of $V(a, e(v, a))$, the expenditure function $E(a, v)$. We also assume that the expenditure required to pass the exam is decreasing in ability and increasing in the minimum score, i.e., $E_{a}(a, v)<0$ and $E_{v}(a, v)>0$. The marginal expenditure required to pass a given score is decreasing in ability, i.e., $E_{a v}(a, v) \leq 0$, the slope of $E(a, v)$ in the $(w, a)$ space is negative and increasing in $v$ : the more selective the university, the flatter the expenditure function.

The utility of individual $i$ attending university $j \in[H, L]$ is given by:

$$
U_{i j}=w_{i}+h\left(a_{i}, \theta_{j}\right)-\mu p_{L}-(1-\mu) E\left(a_{i}, v_{H}\right), \text { with } \mu=\left\{\begin{array}{l}
0, \text { if } j=H \\
1, \text { if } j=L
\end{array}\right.
$$

where human capital $h\left(a_{i}, \theta_{j}\right)$ is a function of individual ability $a_{i}$ and university quality $\theta_{j}$, $w_{i}$ is the individuals income level, $p_{L} \geq 0$ is the private university tuition fee, and $E\left(a_{i}, v_{H}\right)$ are the resources spent by an individual of ability $a_{i}$ to pass the admission test at the public university.

We assume constant marginal utility, thus assuming away risk aversion. In our setting, this assumption is innocuous as we ruled out uncertainty in the returns to higher education. Also, individuals' choice of education investment is discrete, and there is one single consumption good, ruling out the possibility of individuals opting for mixed bundles of goods. Human capital is increasing in the individuals ability at a non-increasing rate, i.e., $h_{a}\left(a_{i}, \theta_{j}\right)>0$ and $h_{a a}\left(a_{i}, \theta_{j}\right) \leq 0$. We also assume that there is complementarity between ability and university quality, i.e., $h_{a \theta}\left(a_{i}, \theta_{j}\right) \geq 0$. As a consequence, the marginal utility of university quality is increasing in ability. The utility of an individual who does not enrol in higher education is $U_{i 0}=w_{i}$.

In the absence of credit markets, the individual is subject to an income constraint, and 
can only afford the public university provided that:

$$
w_{i} \geq \mu p_{L}+(1-\mu) E\left(a_{i}, v_{H}\right), \text { with } \mu=\left\{\begin{array}{c}
0, \text { if } j=H \\
1, \text { if } j=L
\end{array}\right.
$$

Definition 1 Demand for public higher education $D_{H}$ is the set of individuals $i$ such that $U_{i H}>U_{i L}$ and $U_{i H}>U_{i 0}$ and $w_{i} \geqslant E\left(a_{i}, v_{H}\right)$.

An increase in $v_{H}$ by the public university tightens the income constraint (2) and reduces the utility (1) attained at the public university $(j=H)$, thus reducing demand $D_{H}$.

The public university chooses $v_{H}$ to fill capacity. Thus, $v_{H}$ will be such that:

$$
D_{H}=\kappa
$$

Definition 2 Demand for private higher education $D_{L}$ is the set of individuals $i$ such that $U_{i L}>U_{i H}$ and $U_{i L}>U_{i 0}$ and $w_{i} \geqslant p_{L}$.

As expected, demand for the private university, $D_{L}$, is inversely related to $p_{L}$. A higher $p_{L}$ reduces the utility (1) resulting from attending the private university $j=L$ and also tightens the income constraint (2).

The private university chooses $p_{L}$ to maximise profits:

$$
\Pi_{L}=\left(p_{L}-c\left(\theta_{L}\right)\right) D_{L}
$$

\subsection{Equilibrium and surplus}

To proceed with the calibration and simulation, we first define an equilibrium.

Definition 3 An equilibrium is a pair $\left(v_{H}, p_{L}\right)$ such that 
- the public university fills capacity: Eq. (3) is satisfied

- the private university maximises profits: Eq. (4) is maximised

- no individual wishes to change her higher education choice

We can also characterise the allocation of students to universities that maximises the total surplus. Let the surplus associated with one student be the difference between her acquired human capital and the university per capita cost:

$$
S_{i j}=h\left(a_{i}, \theta_{j}\right)-c\left(\theta_{j}\right)
$$

The surplus generated by public higher education will be maximised when for all $i \in D_{H}$ :

$$
h\left(a_{i}, \theta_{H}\right)-c\left(\theta_{H}\right)>h\left(a_{i}, \theta_{L}\right)-c\left(\theta_{L}\right)
$$

and

$$
h\left(a_{i}, \theta_{H}\right)-c\left(\theta_{H}\right)>0 .
$$

Similarly, the surplus generated by private higher education will be maximised when for all $i \in D_{L}:$

$$
h\left(a_{i}, \theta_{L}\right)-c\left(\theta_{L}\right)>h\left(a_{i}, \theta_{H}\right)-c\left(\theta_{H}\right)
$$

and

$$
h\left(a_{i}, \theta_{L}\right)-c\left(\theta_{L}\right)>0 .
$$

Note that this is independent of income. Total surplus will be maximised when students are sorted into schools based on their ability only.

In our quantitative analysis, we will consider the total surplus, i.e., the sum of surpluses of individuals at their allocated universities, and the average surplus, i.e., total surplus at each 
university divided by the respective enrolment at each university. While the total surplus captures both changes in the ability level of students and enrolment levels, the average surplus informs us of the changes in ability level among students enrolled in a given university.

\section{Calibration and simulation}

To study the equilibrium, we now calibrate the model using specific functional forms and parameters from the Brazilian economy. We can then investigate the partition of the population into each higher education alternative (no university, public, or private university) in the presence of credit constraints. Our main goal is to verify to what extent policy alternatives commonly used in many countries help to increase the surplus associated with higher education in a market with credit constraints. The three policy alternatives are: subsidising private university fees, reducing the minimum exam requirement in the public university for low-income individuals, and increasing the public university capacity. In each case, we identify who benefits and who loses from these policies.

We consider the following functional forms:

$$
\begin{array}{r}
h\left(a_{i}, \theta_{j}\right)=a_{i} \theta_{j} \\
E\left(a_{i}, v_{j}\right)=\left(a_{\max }-a_{i}\right) v_{j} \\
c\left(\theta_{j}\right)=\frac{\theta_{j}^{2}}{2},
\end{array}
$$

satisfying the assumptions presented in Section 3. We proxy ability by the IQ test, which is normally distributed with mean 100 and standard deviation 15 :

$$
a \sim \mathcal{N}(100,225)
$$

We set $a_{\max }=136$, as only $1 \%$ of individuals have IQ score larger than 136 . We also assume 
that income is log-normally distributed:

$$
\ln (w) \sim \mathcal{N}\left(\mu_{w}, \sigma_{w}^{2}\right)
$$

Finally, we assume that $\left[\begin{array}{c}a \\ \ln (w)\end{array}\right]$ is distributed bivariate normal with mean $\left[\begin{array}{c}\mu_{a} \\ \mu_{w}\end{array}\right]$ and covariance matrix:

$$
\left[\begin{array}{cc}
\sigma_{a}^{2} & \rho \sigma_{a} \sigma_{w} \\
\rho \sigma_{a} \sigma_{w} & \sigma_{w}^{2}
\end{array}\right]
$$

where $\rho$ is the correlation parameter. When this parameter $\rho=0$, income and ability follow univariate normal distributions. While our main qualitative results remain similar independently of the correlation parameter, we discuss in Section 6 some of the (slight) changes in the outcome levels. An interesting feature is that the correlation parameter affects the surplus generated by the baseline case, i.e., with credit constraints. Intuitively, when income and ability are uncorrelated, all those who can pay enrol, and all levels of ability are equally represented in the intake. In contrast, a high correlation between ability and income implies that among those who can pay the fee, many individuals also have the adequate level of ability, and the surplus generated by the baseline case is larger.

It is essential to allow for the correlation between ability and income. It has long been known that IQ is not a measure of innate ability and that personal experience impacts the IQ level (Simons, 1978). Also, there is a correlation between individual experience and the households socioeconomic background, even if parental stimulation rather than income seems to be the main channel (Heckman, 2006). As in Epple et al. (2017), we use the intergenerational correlation of income as a proxy for the relationship between income and ability. Ferreira and Veloso (2006) estimate the intergenerational correlation of income in Brazil to be equal to 0.58 , more substantial than the 0.4 found in the US. Since household income affects childrens school choices, the intergenerational correlation of income is probably 
an upper bound of the association between parental income and child ability. In Section 6, we show that our results remain qualitatively similar when we consider a correlation of 0.1 and 0.4 .

We calibrate the model parameters, i.e., $\mu_{w}, \sigma_{w}, \kappa, \theta_{h}$, and $\theta_{l}$, to match relevant values of the Brazilian income distribution and educational system in 2000, as shown in Table 1. In panel A, monthly mean and median household earnings are 1,172 and 562 Brazilian reais, respectively. We present the corresponding parameters in Table 2.

\begin{tabular}{lc}
\hline A. Income distribution & \\
Mean household earnings & 1,172 \\
Median household earnings & 562 \\
\hline B. Education & \\
University enrolment - age group 18-24 & $1,705,768$ \\
Total population - age group 18-24 & $23,365,185$ \\
Net enrolment rate - Tertiary - age group 18-24 & $7.3 \%$ \\
University enrolment - all age groups & $2,864,046$ \\
$\quad$ Public (\%) & $30 \%$ \\
$\quad$ Private (\%) & $70 \%$ \\
\hline
\end{tabular}

Table 1: Income and Education Data - Brazil - 2000 Population Census

As shown in Table 1 (panel B), net university enrolment rate at university was $7.3 \%$ in 2000. Since public universities correspond to $30 \%$ of university enrolment, we calibrate the public university capacity, $\kappa$, to $2.2 \%$. We set public university quality, $\theta_{H}=100$, and calibrate private university quality to match approximately total enrolment. In the baseline case, a good approximation is $\theta_{L}=65$, which generates a total enrolment of $7.6 \%$, slightly larger than observed enrolments. ${ }^{14}$

To simulate the model, we generate a grid of 1,000,000 individuals characterised by ability and income levels given by distributions (9) and (10). Considering the functional forms and parameters presented above, we compute equilibrium values for $p_{L}$ and $v_{H}$.

More precisely, we generate a vector of 10,000 values for $p_{L}$ ranging from 2, 000 to $4,500 .{ }^{15}$

\footnotetext{
${ }^{14}$ Due to the discrete nature of the grid, we are unable to achieve a better approximation.

${ }^{15}$ The size of the vector $p_{L}$ increases computation time significantly. Therefore, we initially consider a
} 


\begin{tabular}{lcc}
\hline Income distribution & $\mu_{w}$ & 6.33 \\
& $\sigma_{w}$ & 1.21 \\
Ability distribution & $\mu_{a}$ & 100 \\
& $\sigma_{a}$ & 15 \\
Correlation between $\ln w$ and $a$ & $\rho$ & 0.58 \\
Public university capacity & $\kappa$ & $2.2 \%$ \\
Public university quality & $\theta_{H}$ & 100 \\
Private university quality & $\theta_{L}$ & 65 \\
\hline
\end{tabular}

Table 2: Parameter Calibration

Given $p_{L}$, we identify a $v_{H}$ such that the public university satisfies the capacity constraint and individuals choose optimally between public, private, and no university. For each of these $\left(p_{L}, v_{H}\right)$ pairs, we calculate the private university profit. Equilibrium is then given by the combination $\left(p_{L}, v_{H}\right)$ that maximises the private university profit.

Table 3 presents the results for the baseline case with credit constraints. At equilibrium, $p_{L}=3,569.7$. The admission score for the public university is $v_{H}=300.8$. Therefore, an individual with average ability, i.e., $a=100$, needs to spend $10,828.8$ to be admitted to the public university. This amount would correspond to the cost of private secondary education, for example.

\begin{tabular}{lc}
\hline$p_{L}$ & $3,569.7$ \\
$v_{H}$ & 300.8 \\
& \\
Enrolment (\%) & \\
Public university & 2.2 \\
Private university & 5.4 \\
\hline
\end{tabular}

Table 3: Equilibrium - Results - Baseline with credit constraints

In the absence of credit constraints, individuals choose university by ability only. Our assumptions on the human capital production function and costs imply that the more able students choose the high-quality university. Panel (a) of Figure 1 depicts a hypothetical larger range, from 0 to 10,000 , and a vector $p_{L}$ with 1,000 (equally spaced) values. We simulate the baseline and all the policy scenarios and verify that $p_{L} \in[2,000,4,500]$ in equilibrium. We then limit the range of $p_{L}$ to $[2,000,4,500]$ and raise the number of vector values to 10,000 in that smaller range, increasing the precision of our simulation significantly. 
equilibrium without credit constraints, which is our simulation benchmark. Students are allocated based on ability only. Higher ability students attend the (high-quality) public university until full capacity is met. Lower ability students attend the (lower quality) private university until they are no longer willing to pay, and lowest ability students attend no university. Assuming that the return to public university education exceeds its cost, the allocation of students to the public university maximises surplus given capacity constraints and the private university tuition fee. ${ }^{16}$

Panel (b) on Figure 1 shows the effects of borrowing constraints in our baseline. Note that, in both panels, the number of students in the public university coincides. The size of the areas differs since students are unevenly distributed in the grid, due to our assumptions on the income and ability distributions.

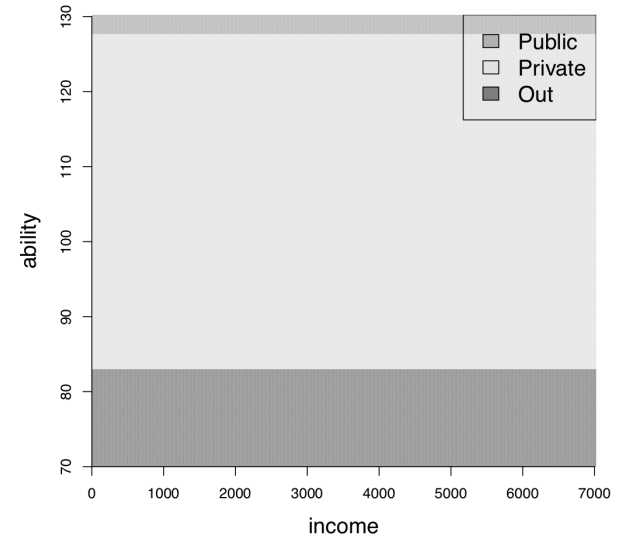

(a) Benchmark (without credit constraints)

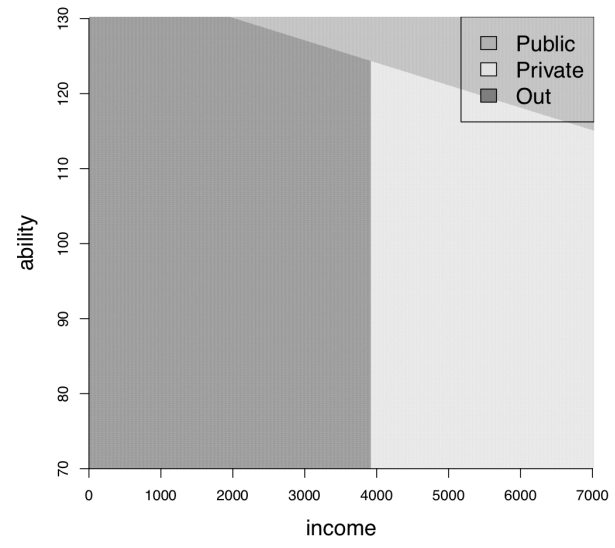

(b) Baseline (with credit constraints)

Figure 1: Benchmark and baseline equilibrium

The comparison of the baseline and benchmark illustrates the impact of the lack of credit markets. First, high-ability-low-income individuals cannot afford the preparation costs

\footnotetext{
${ }^{16}$ The benchmark equilibrium differs from the outcome that maximises the surplus in two respects. First, students are allocated to the public university until full capacity is met, not until human capital produced equals the per capita cost $c\left(\theta_{H}\right)$. Second, students are allocated to the private university until they are no longer willing to pay $p_{L}$, not until their human capital equals the per capita $\operatorname{cost} c\left(\theta_{L}\right)$.
} 
required to pass the admission exam at the public university. To fill capacity, due to the unequal distribution of income and ability, the public university needs to lower the admission standard very much. The profile of students who attend the private university changes dramatically. Because some higher-income students now enrol at the public university, the private university needs to lower the fee to attract more (lower-income) students. Some students, for whom the benefit of investing in higher education did not exceed the cost in the benchmark, can now afford private tuition fees and enrol at the private university. Finally, individuals with the lowest incomes do not enrol at any university. Due to the unequal income distribution in Brazil, these individuals represent a sizeable proportion of the population.

\section{Policies counterfactuals}

We now consider three policies that could, in principle, increase the surplus, bringing the allocation of students in the public university closer to our simulation benchmark depicted in panel (a) of Figure 1. The first is a subsidy to cover the private university tuition fee for low-income individuals partially. The second is an affirmative action policy, which consists of a reduction, for low-income individuals, in the requirement for passing the public university exam. In both cases, we set the income eligibility threshold to three times the minimum wage per capita, which was used by the Brazilian scholarship program, ProUni. In 2000, the minimum wage was 151, and there were, on average, 3.73 individuals per household, amounting to an income eligibility threshold of 1,689.7. Finally, we consider an expansion in the public university capacity. In each case, we investigate how the public and private universities react to these policies and the impact of these policies on total university enrolment and the surplus associated with higher education. We also briefly discuss the costs associated with each of these policies and the possibility of combining them. For expositional 
clarity, we present the surplus figures in Appendix A.

\subsection{Private university fee subsidy}

Assume the government provides a subsidy $s p_{L}$ with $\left.\left.s \in\right] 0,1\right]$ to eligible individuals willing to enrol at the private university. Figure 2 represents the equilibrium allocation of students for (a) $s=0.2$, (b) $s=0.5$, and (c) $s=0.8$. Panel (a) shows that the introduction of a small subsidy covering $20 \%$ of tuition fees does not affect the allocation, as it does not relax eligible individuals' budget constraints. Larger subsidies, corresponding to $50 \%$ or $80 \%$ of tuition fees, do affect their choices, providing incentives to lower-income individuals to enrol in the private university. Interestingly, this phenomenon occurs among individuals of all ability levels. Even low-ability individuals who would not find it optimal to enrol in private universities if they had access to credit, would decide to join the private university in the presence of tuition fee subsidies (see panel (a) of Figure 1). Therefore, a large subsidy induces some low-ability students to enrol in private universities even when it is not optimal to do so, reducing the average surplus of the private university sector (Figure 9, panel (e)). However, it also enrols many low-income-high-ability individuals, generating a large total surplus (Figure 9, panel (b)). The simulation results also show that a relatively lowincome eligibility threshold may prevent middle-income students from joining the private university, generating discontinuities in higher education participation relative to income. Still, participation increases considerably. Total enrolment is initially at $7.6 \%$, as in the baseline case, but raises to $13.4 \%$ with a subsidy of $50 \%$, and reaches $21.6 \%$ when the subsidy is of $80 \%$ of tuition fees.

Note also that the private university fee subsidy does not affect the admission requirements at the public university, as shown in panel (a) of Figure 3. Thus, this policy does not impact the surplus associated with the public university allocation (Figure 9, panel (a)). As a result, the total surplus of higher education, unchanged until the subsidy reaches $50 \%$ of 


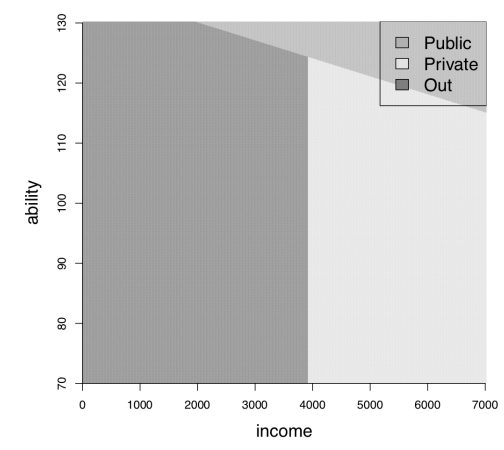

(a) $s=0.2$

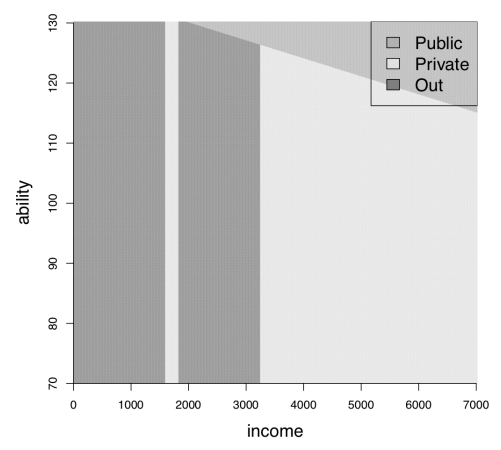

(b) $s=0.5$

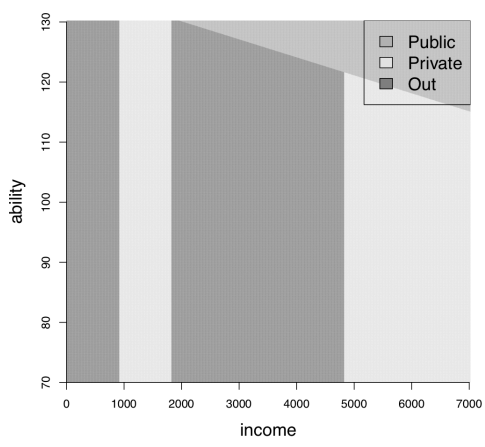

(c) $s=0.8$

Figure 2: Student allocation with private university fee subsidy

the fee, increases continuously as the subsidy grows above this threshold due to increased participation (Figure 9, panel (c)).

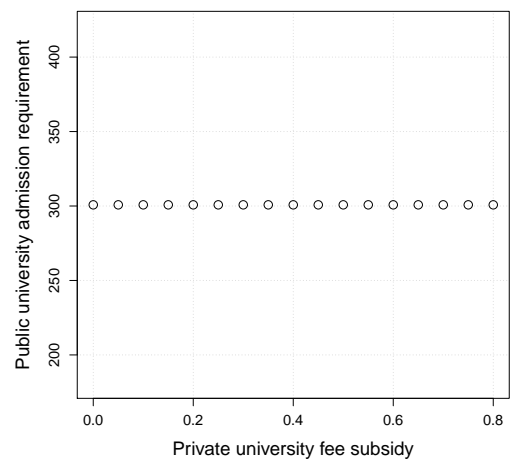

(a) $v_{h}(s)$

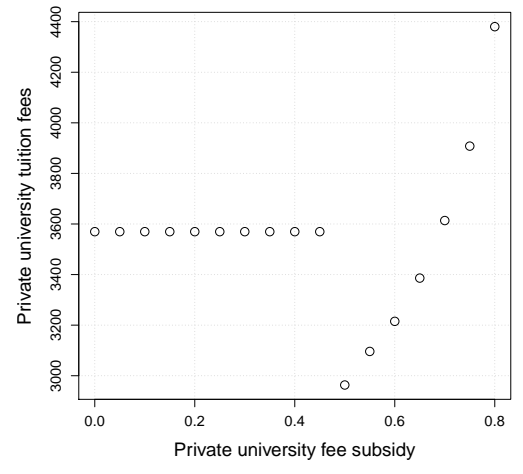

(b) $p_{l}(s)$

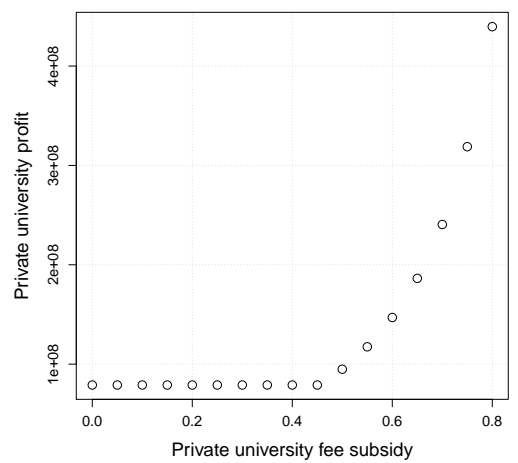

(c) $\pi_{l}(s)$

Figure 3: Equilibrium with private university fee subsidy

It is also worth noting that if the subsidy rate is large enough, it impacts the pricing strategy of the private university and raises its profits. While the private university may initially decrease the tuition fee to attract poorer students, who are numerous, it raises the fees exponentially as the level of subsidy increases over 50\% (panel (b) of Figure 3). For subsidies larger than $70 \%$ of the fee, the full fee is larger than without subsidies, harming some 
students from middle-income backgrounds. However, many more individuals who are more disadvantaged, and eligible to receive the subsidy, are still able to enrol when the subsidy exceeds $70 \%$ of the fee. Also, despite the increase in total participation in higher education and the surplus as the private university recruits additional students, the allocation of ability types in the public university does not change, and many high-ability individuals with low and medium incomes still do not have access to university under this policy scenario. The cost of this private university fee subsidy can be sizeable (see section 5.4 for a discussion of the costs of the different policies).

\subsection{Affirmative action}

In this section, we consider a reduction of $b \%$ in the expenditure required for acceptance at the public university for low-income individuals. To render the policies comparable, we adopt the same income eligibility threshold as in the previous subsection. As Figure 4 shows, this affirmative action policy benefits some high-ability-poor-individuals when we consider a reduction in the required expenditure of $20 \%$ or $50 \%$. Figure 10 (panel (d)) represents the evolution of the average surplus at the public university as $b$ increases. Initially, as the proportion of low-income-high-ability individuals admitted at the public university increases, the surplus generated by the public university rises. However, as the affirmative action policy becomes more aggressive, reducing in $80 \%$ the expenditure required for admission at the public university, it attracts too many low-income individuals with relatively lower ability levels, leading to a surplus reduction.

The reason for this drop in the surplus is that, since the public university capacity is constant, the general requirement to access the public university $v_{H}$ necessarily increases as $b$ increases (see panel (a) of Figure 5). Some relatively high-ability individuals with high incomes are no longer admitted at the public university, and turn to the private university, with initially positive effects on the surplus generated in the private university (Figure 10, 


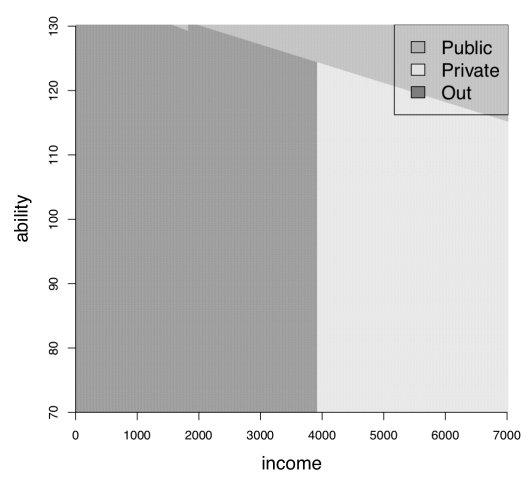

(a) $b=20 \%$

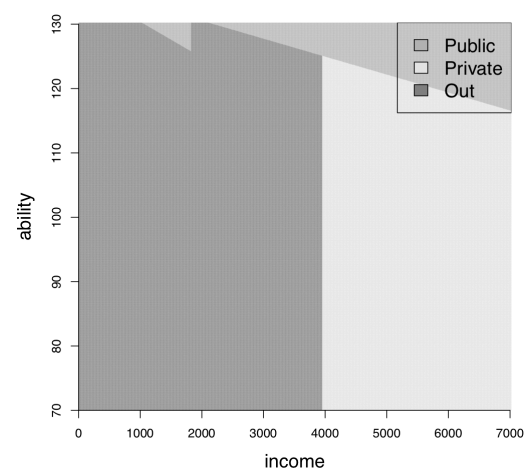

(b) $b=50 \%$

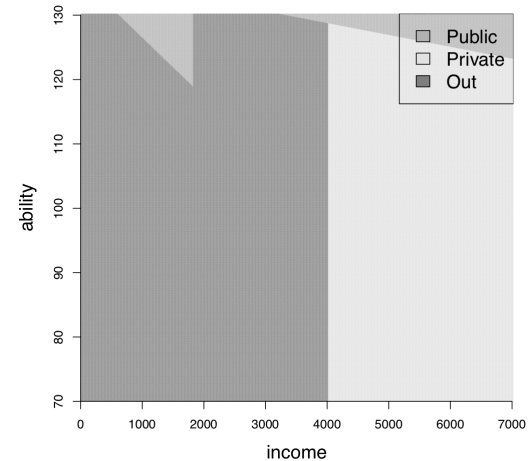

(c) $b=80 \%$

Figure 4: Student allocation with affirmative action

panel (b)). However, since these individuals can pay more, the fee at the private university ends up increasing for sufficiently high subsidies on low earners at the public university, as shown in panel (b) of Figure 5, also generating a boost in private university profits (panel (c) Figure 5).

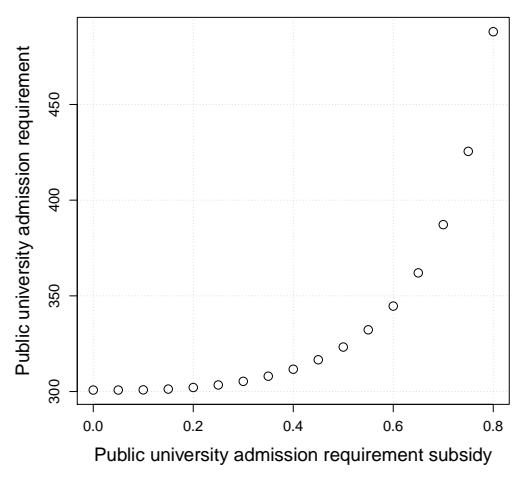

(a) $v_{h}(b)$

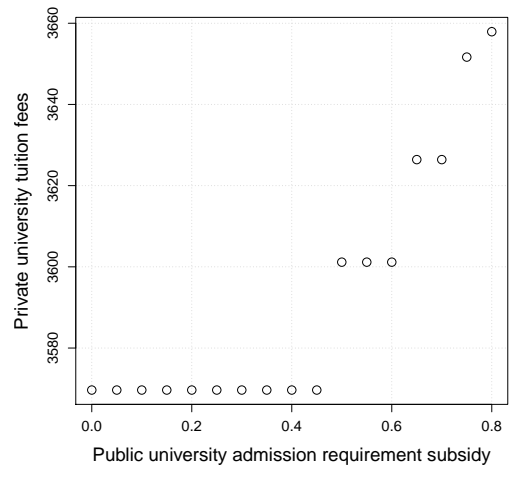

(b) $p_{l}(b)$

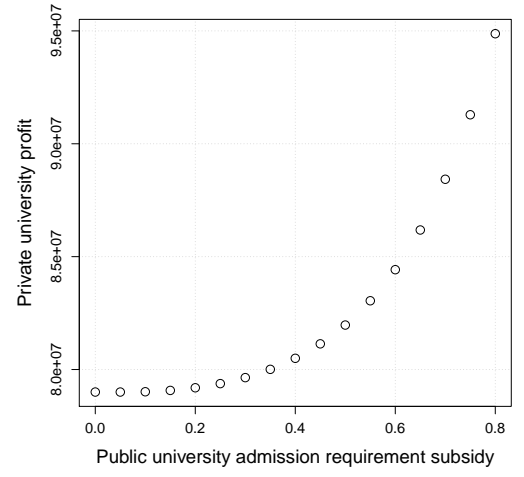

(c) $\pi_{l}(b)$

Figure 5: Equilibrium with affirmative action

With the affirmative action policy, participation in higher education increases overall, but on a very narrow range, from $7.6 \%$ to $8.3 \%$, following a reduction of $80 \%$ in exam preparation costs. Thus, affirmative action tends to improve the surplus associated with the 
public university allocation of students relative to the benchmark case, but this improvement is non-monotonic. At some point near $b=50 \%$, the private university fee jumps up, reducing the global surplus to levels close to the ones obtained at the benchmark (Figure 10, panel (c)). As the reduction in the requirement to attend the public university for low-income students continues to increase, more high-income high ability individuals turn to the private university, and total surplus grows again. The total surplus per capita increases continuously, as this policy improves the allocation of students to universities.

\subsection{Increase in public university capacity}

We now turn to the analysis of the effects of increasing public university capacity. As shown in Figure 6, the expansion of public university places increases participation among lowerincome-high-ability individuals, but it benefits disproportionately high-income individuals of various ability levels who move from the lower quality private university to the higher quality public university.

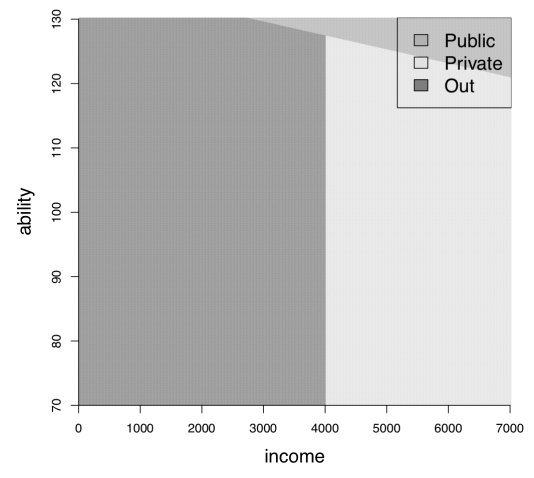

(a) $\kappa=1 \%$

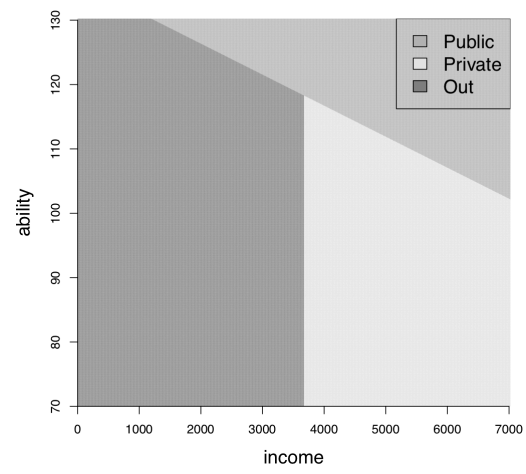

(b) $\kappa=5.5 \%$

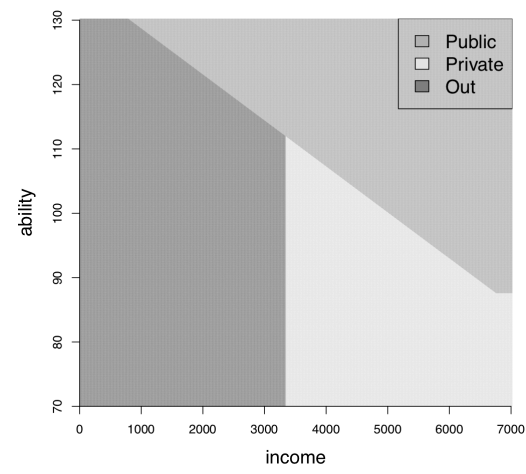

(c) $\kappa=10 \%$

Figure 6: Student allocation with increasing public university capacity

As its capacity increases, the public university needs to lower academic standards $v_{H}$ to fill the additional places, as shown in Figure 7. As more students enrol at the higher 
quality public university, the private university reacts by reducing the fee. Still, the number of students enrolled at the private university falls. Consequently, profits at the private institution go down as the number of places in the public university increases.

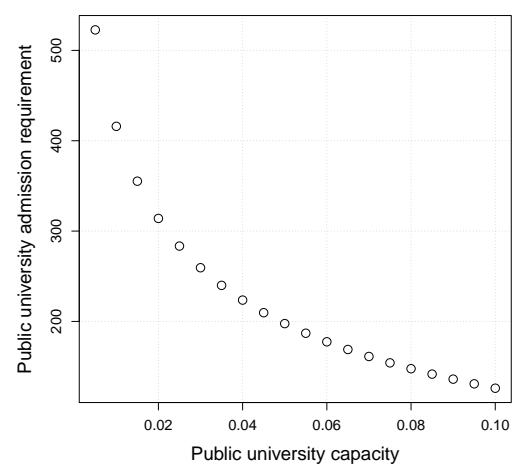

(a) $v_{h}(\kappa)$

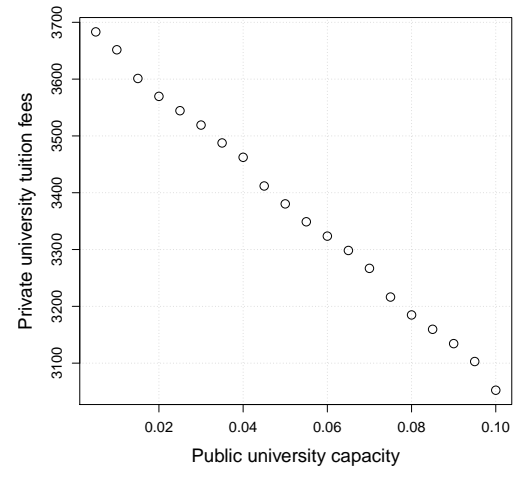

(b) $p_{l}(\kappa)$

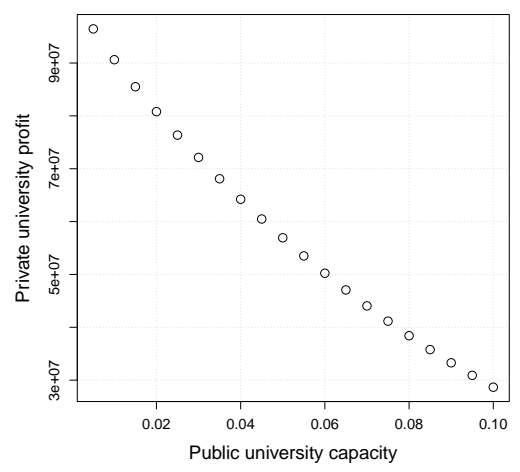

(c) $\pi_{l}(\kappa)$

Figure 7: Equilibrium with increasing public university capacity

Total participation in higher education increases steadily with the number of public university places since the number of new places at the public university more than compensates the reduction in private university enrolment. For instance, when public university places correspond to $1 \%$ of the total population, total university enrolment is $6.9 \%$. An increase in public university places to $10 \%$ leads to total university enrolment of $13 \%$. However, participation remains heavily biased toward high-income individuals, especially in the public university, and some of the ablest do not gain access to any university. The increase in public university capacity leads to a decrease in the average surplus associated with the public university system (Figure 11, panel (d)), as the mean ability of public university students decreases monotonically. Still, the total surplus increases steadily as the number of public university places grows, as illustrated in panel (c), Figure 11. 


\subsection{Discussion}

We now discuss the relative effects of the three policies accounting for their costs and comment on the possibility of combining them.

First, we have seen that private university tuition fee subsidies are very effective in increasing enrolment. Although partially subsidising the private tuition fee of one student is far less costly than funding one public university place of greater quality, the total cost associated with this policy is far from negligible. In our exercise, the cost of a public place is 5,000 and the per beneficiary subsidy is approximately 1,480 when $s=0.5$, raising to more than 3,500 when $s=0.8$. The public budget would need to increase by $623 \%$ to achieve a threefold increase in enrolment, i.e., from $7.6 \%(s=0)$ to $21.6 \%(s=0.8)$.

Second, reducing the public university admission requirement for lower-income individuals has a negligible impact on total enrolment, but improves the allocation of students, raising total surplus. This policy has the advantage of being neutral from a public finance perspective, making it an attractive option when increasing participation is not the primary goal.

Last, the expansion of high-quality public university places is the most costly policy, as it implies raising enrolment at the most expensive alternative. Indeed, the nearly two-fold increase in enrolment (from $6.9 \%$ to $13 \%$ ) implies a 2,000\% increase in the public university budget. Total surplus increases, but this masks a decline in surplus at the private university sector.

Since it entails no additional cost, affirmative action is a policy that could be easily combined with other policies, contributing to a higher surplus. Among the policies evaluated here, private university subsidies are the most effective in raising participation. Thus, a combination of affirmative action and private university subsidies could improve both objectives at a lower cost than any other combination of policies. 


\section{Robustness checks}

We now explore the sensitivity of our results to changes in the income-ability correlation. Figure 8 summarises the effects of the private university fee subsidy $s$, the public university admission requirement subsidy $b$, and the public university capacity $\kappa$ on the decision variables of the universities (the public university admission requirement, $v_{H}$, in the upper panel, and the private university tuition fee, $p_{L}$, in the lower panel) for different correlation levels, i.e., 0.1, 0.4, and 0.58, the last one corresponding to our main specification.

Figure 8 shows that marginal effects remain very similar for different levels of the incomeability correlation. There are only changes in the $p_{L}$ and $v_{H}$ levels. The admission requirement level is higher when the correlation between income and ability is more considerable. In this case, a higher proportion of high ability individuals can pay the costs required to pass the exam and hence, a tougher exam is required to restrict admission at the public university. Similarly, willingness to pay for an education at the private university, which depends on ability, is also larger for a given income level. For this reason, the fee that maximises profits increases with the correlation parameter.

\section{Conclusion}

In this paper, we have extended the model in ? to allow for the interaction of public and private universities when students cannot borrow to pay fees or admission exam preparation costs. Although loan programs seem the natural way to address borrowing constraints, they are generally disadvised in developing countries and therefore, out of the scope of our paper.

We have calibrated the model to the higher education sector in Brazil, and we have simulated three commonly used policies. First, we have considered a partial subsidy of the private university tuition fee for students from low-income households. The salient feature of this case is that the public university does not react and public university admissions remain 


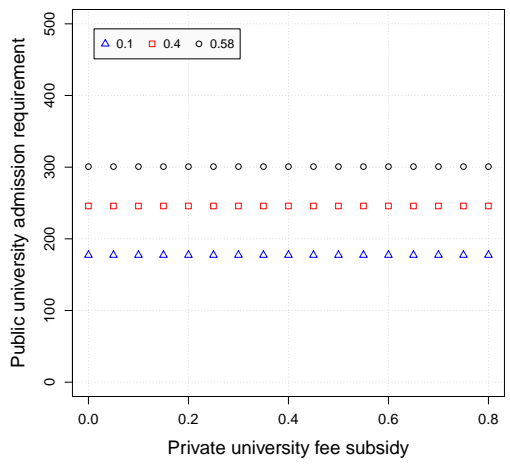

(a) Public university (Total)

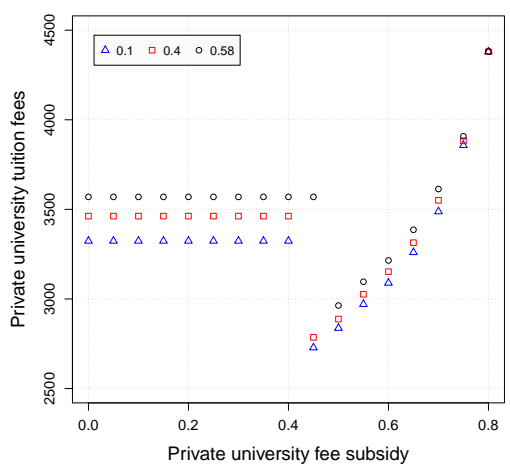

(d) Public university (Average)

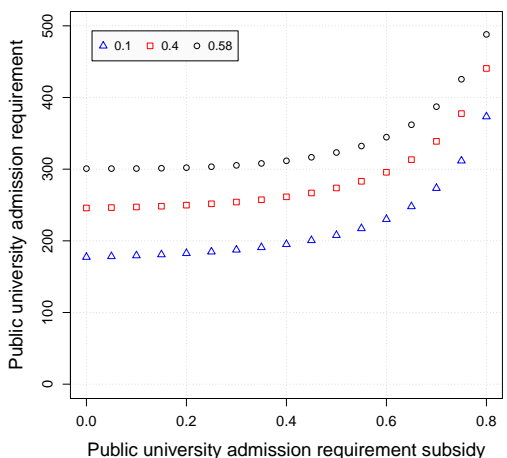

(b) Private university (Total)

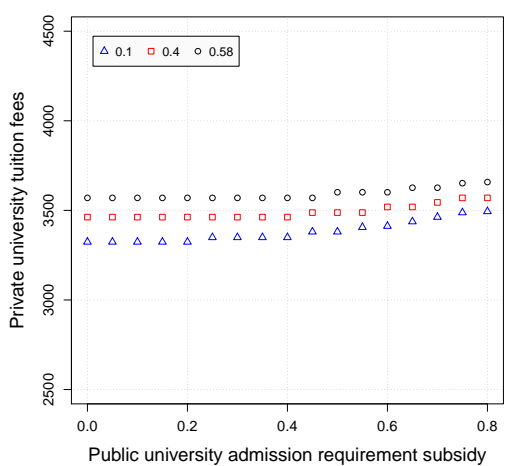

(e) Private university (Average)

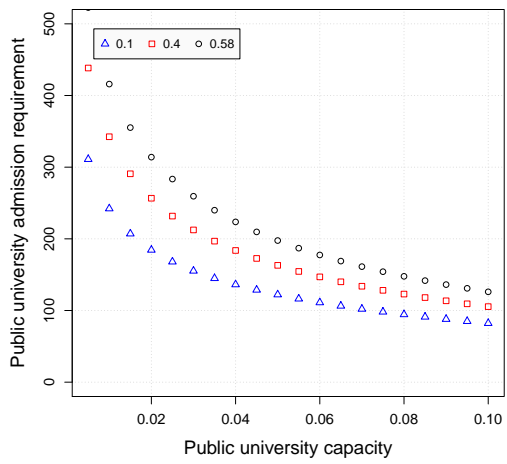

(c) All universities (Total)

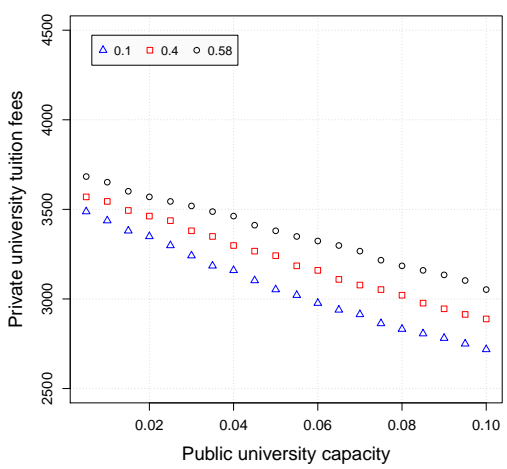

(f) All universities (Average)

Figure 8: Main results with different ability-income correlation levels.

constant. Private university fees remain constant, then drop, and finally increase steadily as the subsidy rate increases. Second, we have inquired into the role of affirmative action policies. To this end, we have assumed that the public university reduces the academic standard required for admission of low-income students. As this reduction increases, more able students from low-income backgrounds enrol at the public university, improving the (per student) surplus associated with the public university. The general academic standard goes up, harming, as expected, middle and high-income students. The private university, at first unaffected, increases the tuition fee if the reduction in the academic requirement for low-income students is sufficiently significant. Last, we have explored the effect of increasing 
the number of public university places. In this case, the private university reacts by lowering the fee. Public university expansion is the only policy that reduces private university profits, continuously as the number of public university places increases. However, university enrolment grows slowly, and many high ability individuals cannot obtain a university education.

In terms of the relative costs, increasing public university capacity is the most expensive option, but raises both participation and the total surplus. Affirmative action policies are revenue neutral and, although they have a negligible effect on total university enrolment, they increase total surplus. Private university subsidies prove most effective to increase access to university and the surplus, but only if they cover more than $50 \%$ of the fee. Hence, although less expensive than expanding public university places, the amount of private university fee subsidies also needs to be sizeable to be effective.

Our model is highly stylised but proves useful to understand some of the dynamics observed in the Brazilian higher education system. There is evidence that Brazilian universities have increased tuition fees as a response to the availability of student credit (Duarte and de Mello, 2016). Because there is low enforcement of loan repayments, this programs amounted to a $100 \%$ subsidy of university fees for most students. Thus, the predictions of our model are in line with these empirical findings. The use of affirmative action policies changed the profile of students enrolled in public universities, making it less advantaged on average without compromising academic achievement, especially for moderate policies (Estevan et al., 2019). This fact is also in line with our results. Finally, participation in higher education has increased steadily over the last few years, and our results would suggest that scholarships (or loans without strict enforcement) have probably been the central policies contributing to that.

Our approach also confirms the importance of accounting for the reactions of universities to public policies in a competitive environment. Given our benchmark, it seems that 
an affirmative action policy that balances the abilities of students admitted at the public university would increase the surplus more than an expansion in the number of places at the public university. However, private university fees stay constant or increase in the former case, while they fall steadily in the latter. As a consequence, total higher education surplus increases faster with the number of public places. Finally, the distribution of income is also key to explain the potential effects of different policies. In a high inequality society such as Brazil, subsidies to private universities need to be very large to induce any change in participation. 


\section{References}

Barigozzi, F. and C. A. Ma (2018): "Product differentiation with multiple qualities," International Journal of Industrial Organization, 61, 380-412.

Benassi, C., M. Castellani, and M. Mussoni (2016): "Price equilibrium and willingness to pay in a vertically differentiated mixed duopoly," Journal of Economic Behavior \&3 Organization, 125, 86-96.

Bertrand, M., R. Hanna, and S. Mullainathan (2010): "Affirmative action in education: Evidence from engineering college admissions in India," Journal of Public Economics, 94, $16-29$.

Brunello, G. and L. Rocco (2008): "Educational standards in private and public schools," The Economic Journal, 118, 1866-1887.

Chapman, B. (2016): "Income contingent loans in higher education financing," IZA World of Labor, 227, 1-10.

Cremer, H. and D. Maldonado (2013): "Mixed oligopoly in education," TSE Working Papers 13-381, Toulouse School of Economics (TSE).

Cremer, H., M. Marchand, and J.-F. Thisse (1991): "Mixed oligopoly with differentiated products," International Journal of Industrial Organization, 9, 43-53.

De Fraja, G. (2004): "Private and public schools: Theoretical considerations," in C. Lucifora and D. Checchi, eds., Education, Training and Labour Market Outcomes in Europe, London: Palgrave Macmillan UK, 38-68.

Del Rey, E. (2009): "Can state university fees increase welfare? A mixed oligopoly approach," Journal of Institutional and Theoretical Economics, 165, 670-683. 
Delbono, F., V. Denicolo, and C. Scarpa (1996): "Quality choice in a vertically differentiated mixed duopoly," Economic Notes, 25, 33-46.

Duarte, I. and J. de Mello (2016): "The effect of the availabilty of student credit on tuitions: Testing the Bennet hypothesis using evidence from a large-scale student loan program in Brazil," 2016 Meeting Papers 1451, Society for Economic Dynamics.

Epple, D. and R. E. Romano (1998): "Competition between private and public schools, vouchers, and peer-group effects," American Economic Review, 88, 33-62.

Epple, D., R. E. Romano, S. Sarpça, and H. Sieg (2017): “A general equilibrium analysis of state and private colleges and access to higher education in the U.S." Journal of Public Economics, 155, 164-178.

Estevan, F., T. Gall, and L.-P. Morin (2019): "Redistribution without distortion: Evidence from an affirmative action program at a large Brazilian university," Economic Journal, $129,1182-1220$.

Fernandez, R. and J. Gali (1999): "To each according to . . . ? Markets, tournaments, and the matching problem with borrowing constraints," Review of Economic Studies, 66, $799-824$.

Ferreira, S. G. and F. A. Veloso (2006): "Intergenerational mobility of wages in Brazil," Brazilian Review of Econometrics, 26, 181-211.

Grilo, I. (1994): "Mixed duopoly under vertical differentiation," Annales d'Économie et de Statistique, 33, 91-112.

Heckman, J. J. (2006): "Skill formation and the economics of investing in disadvantaged children," Science, 312, 1900-1902. 
Horch, D. (2014): "As demand for education rises in Brazil, for-profit colleges fill the gap," The New York Times, 19 June. Available at: https://dealbook.nytimes.com/2014/06/19/as-demand-for-education-rises-in-brazilfor-profit-colleges-fill-the-gap/. (Accessed: 8 October 2019).

INEP/MEC (2010): "[Public expenditures per student by education level, nominal values]. Investimentos públicos por estudante por nível de ensino, valores nominais (in Portuguese)," INEP website (http://portal.inep.gov.br/indicadores-financeiros-educacionais).

Ishibashi, K. and T. Kaneko (2008): "Partial privatization in mixed duopoly with price and quality competition," Journal of Economics, 95, 213-231.

Jofre-Bonet, M. (2000): "Health care: Private and/or public provision," European Journal of Political Economy, 16, 469-489.

Knobel, M. and R. Verhine (2017): "Brazil's for-profit higher education dilemma," International Higher Education, 89, 23-24.

Laine, L. T. and C. A. Ma (2017): "Quality and competition between public and private firms," Journal of Economic Behavior \&3 Organization, 140, 336-353.

Levy, D. C. (2018): "Global private higher education: an empirical profile of its size and geographical shape," Higher Education, 76, 701-715.

Menezes-Filho, N. and D. F. Nunez (2012): "[Estimating private spending on education in Brazi] Estimando os gastos privados com educação no Brasil," Technical Report 3, Insper Policy Paper.

Oliveira, T. (2006): "Tuition fees and admission standards: how do public and private universities really compete for students?" Discussion Papers in Economics 06/6, Division of Economics, School of Business, University of Leicester. 
Ramos, J. and B. Herskovic (2017): "Promoting educational opportunities: Long-run implications of affirmative action in college admissions," 2017 Meeting Papers 1552, Society for Economic Dynamics.

Romero, L. and E. Del Rey (2004): "Competition between public and private universities: Quality, prices and exams," Economics Working Papers we046423, Universidad Carlos III, Departamento de Economía.

Salto, D. J. (2018): "To profit or not to profit: the private higher education sector in Brazil," Higher Education, 75, 809-825.

Sanjo, Y. (2009): "Quality choice in a health care market: a mixed duopoly approach," The European Journal of Health Economics, 10, 207-215.

Simons, R. L. (1978): "The meaning of the IQ-delinquency relationship," American Sociological Review, 43, 268-270.

Times Higher Education (2019): "The world university rankings," Https://www.timeshighereducation.com/.

Tomori, F. (2018): "Mixed duopoly in education with vouchers," Working Papers 2072/306548, Universitat Rovira i Virgili, Department of Economics. 


\section{A Appendix: Additional Figures}

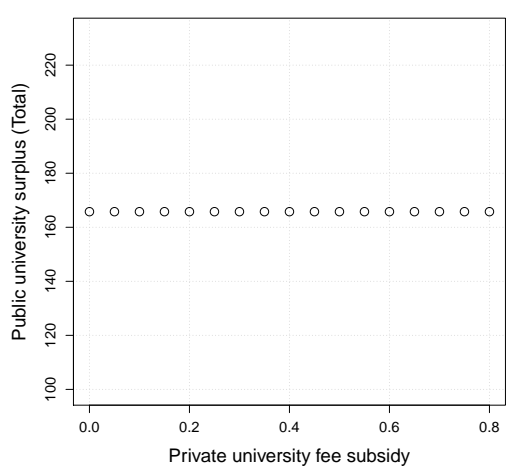

(a) Public university (Total)

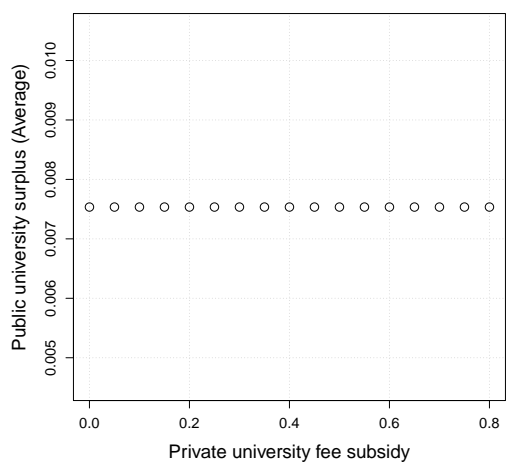

(d) Public university (Average)

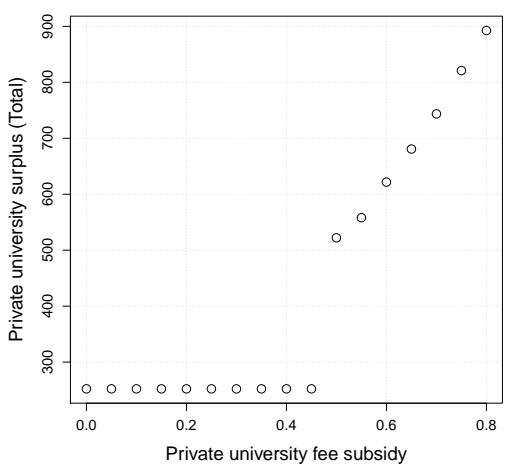

(b) Private university (Total)

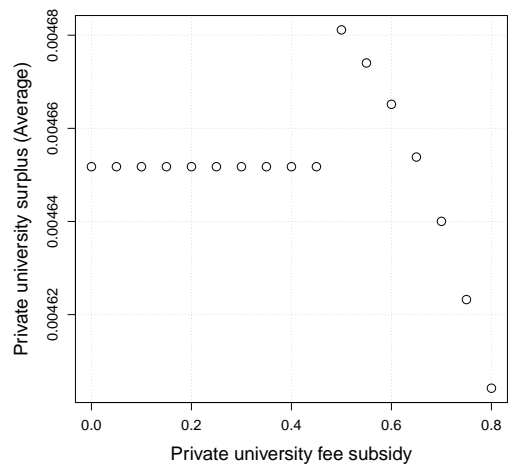

(e) Private university (Average)

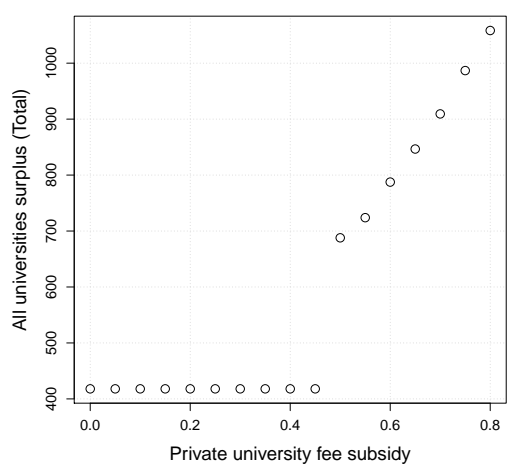

(c) All universities (Total)

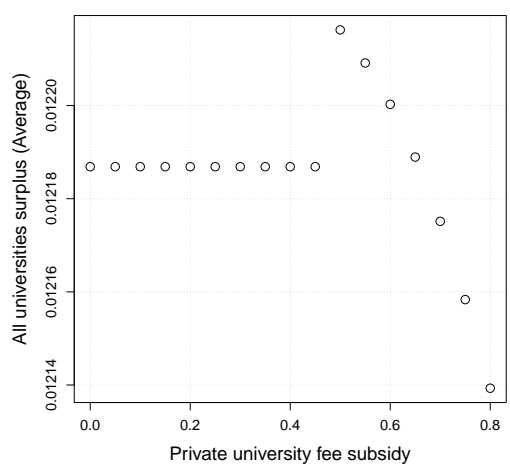

(f) All universities (Average)

Figure 9: Surplus with private university fee subsidy 


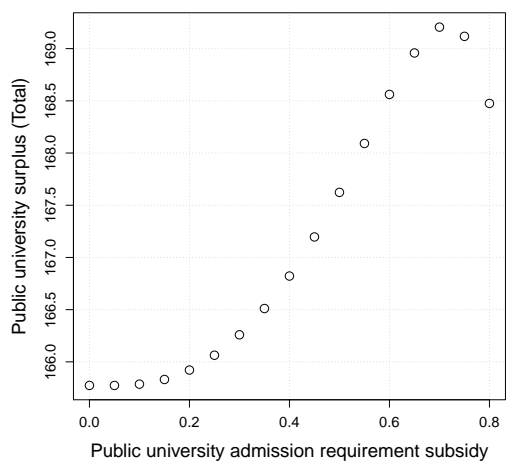

(a) Public university (Total)

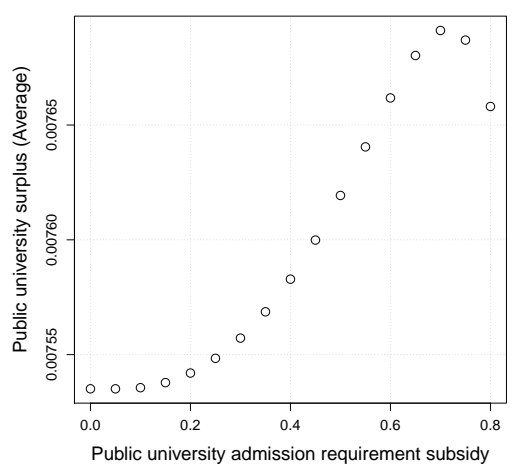

(d) Public university (Average)

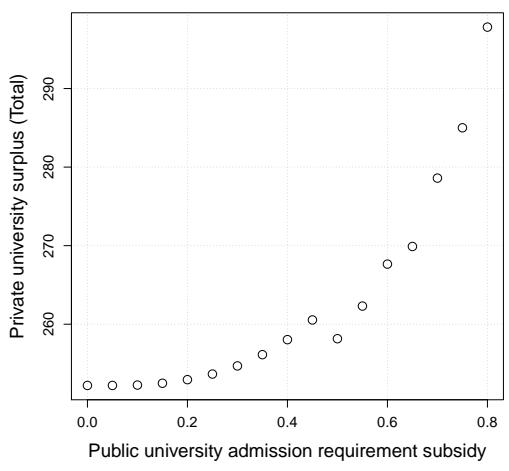

(b) Private university (Total)

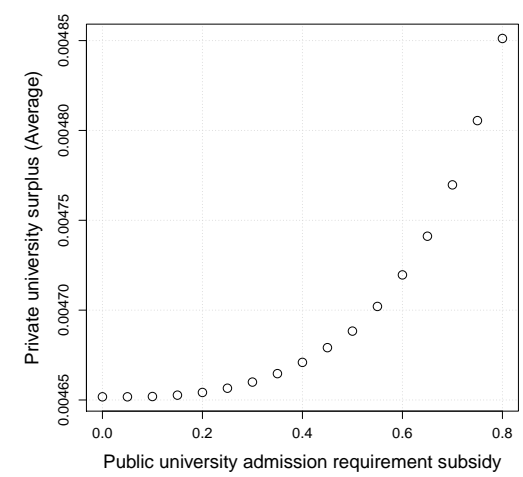

(e) Private university (Average)

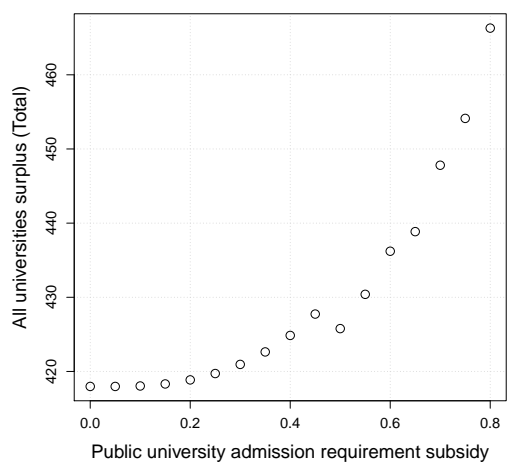

(c) All universities (Total)

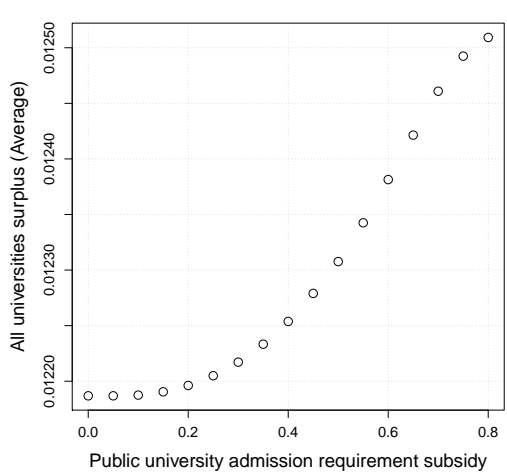

(f) All universities (Average)

Figure 10: Surplus with affirmative action 


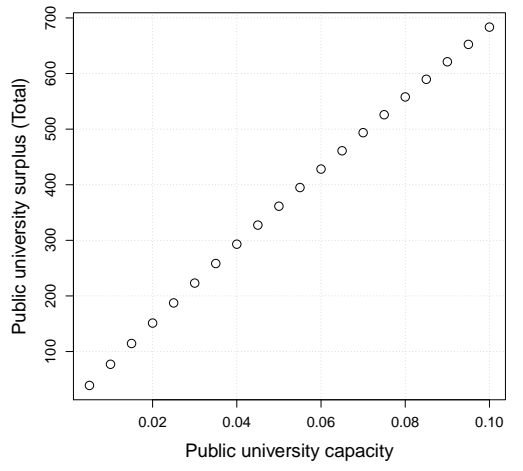

(a) Public university (Total)

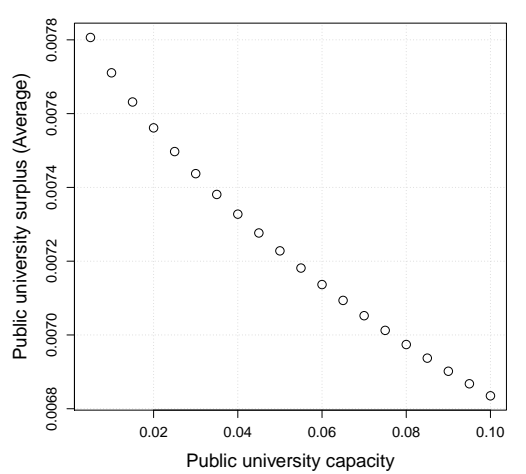

(d) Public university (Average)

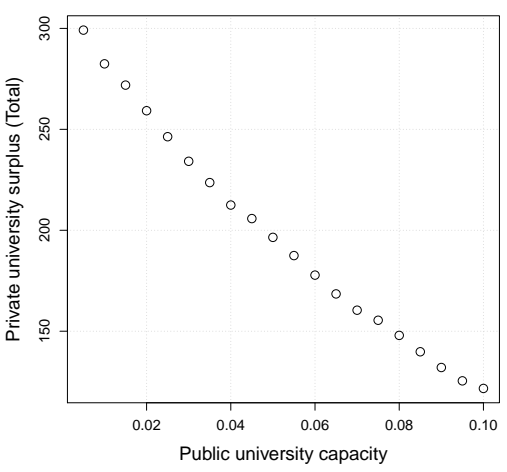

(b) Private university (Total)

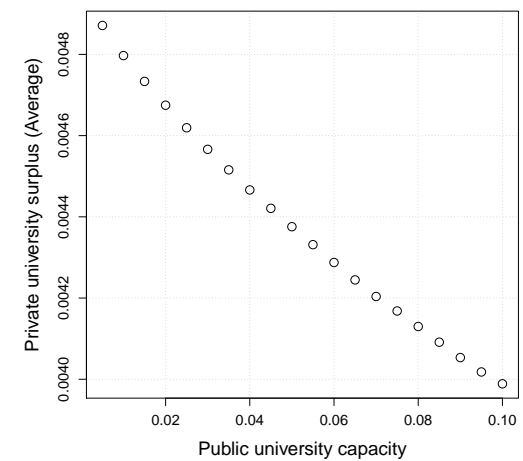

(e) Private university (Average)

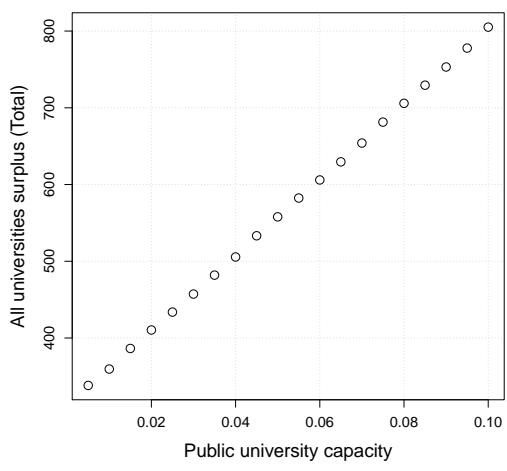

(c) All universities (Total)

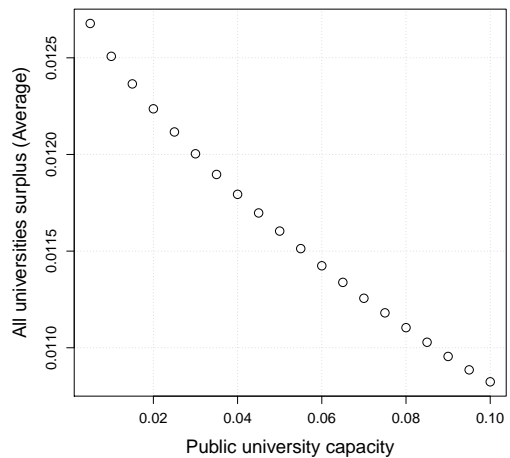

(f) All universities (Average)

Figure 11: Surplus with increases in public university capacity 